\title{
Analysis of conventional versus advanced pelvic floor muscle training in the management of urinary incontinence after radical prostatectomy: a systematic review and meta-analysis of randomized controlled trials
}

\author{
Dechao Feng ${ }^{\#}$, Shengzhuo Liu ${ }^{\#}$, Dengxiong Li^${ }^{\wedge}$, Ping Han^, Wuran Wei^ \\ Department of Urology, Institute of Urology, West China Hospital, Sichuan University, Chengdu, China \\ Contributions: (I) Conception and design: D Feng; (II) Administrative support: P Han; (III) Provision of study materials or patients: D Feng, S Liu, D \\ Li; (IV) Collection and assembly of data: D Feng, S Liu; (V) Data analysis and interpretation: D Feng, S Liu; (VI) Manuscript writing: All authors; (VII) \\ Final approval of manuscript: All authors. \\ "These authors contributed equally to this work. \\ Correspondence to: Wuran Wei. Department of Urology, Institute of Urology, West China Hospital, Sichuan University, Guoxue Xiang \#37, Chengdu \\ 610041, China. Email: weiwuranwch@126.com.
}

\begin{abstract}
Background: The underutilization of additional supportive muscles is one of the potential reasons for suboptimal efficacy of conventional pelvic floor muscle training (CPFMT). The present study concentrates on any advantage of advanced pelvic floor muscle training (APFMT) in patients with urinary incontinence (UI) after radical prostatectomy (RP).
\end{abstract}

Methods: Literature search was conducted on PubMed, Embase, Cochrane Library and Web of Science from database inception to February 2020. The data analysis was performed by the Cochrane Collaboration's software RevMan 5.3.

Results: Both APFMT and CPFMT groups indicates superiority over baseline in terms of pad number, the International Consultation on Incontinence Questionnaire-Short Form (ICIQ-SF) score, pad weight at short-term follow-up, and PFME and PFMS at intermediate-term follow-up. No adverse events were reported in all included studies. Patients receiving APFMT had a similar attrition rate to those receiving CPFMT (18/236 vs. 22/282, $\mathrm{P}=0.61)$. Compared to CPFMT group, APFMT group provided intermediateterm advantages in terms of pad number (MD: $-0.75,95 \% \mathrm{CI}:-1.36$ to -0.14 ; $\mathrm{P}=0.02)$, ICIQ-SF score (MD: $-3.79,95 \%$ CI: -5.89 to -1.69 ; $\mathrm{P}=0.0004$ ), PFME (MD: $1.93,95 \% \mathrm{CI}: 0.99$ to $2.87 ; \mathrm{P}<0.0001$ ) and pad weight (MD: $-1.40,95 \% \mathrm{CI}:-1.70$ to $-1.00 ; \mathrm{P}<0.00001$ ).

Conclusions: Current evidence indicated that APFMT might facilitate the recovery of UI after RP according to intermediate-term advantages over CPFMT in terms of pad number, ICIQ-SF score, PFME and pad weight. Further standardized, physiotherapist-guided and well-designed clinical trials conducted by large multicenter and experienced multidisciplinary clinicians are still warranted.

Keywords: Pelvic floor muscle training; Pfilates; hypopressives; radical prostatectomy; meta-analysis

Submitted Feb 19, 2020. Accepted for publication Sep 04, 2020.

doi: $10.21037 /$ tau-20-615

View this article at: http://dx.doi.org/10.21037/tau-20-615

\footnotetext{
^ Dechao Feng ORCID: 0000-0002-8267-9920; Shengzhuo Liu ORCID: 0000-0001-8424-2549; Dengxiong Li ORCID: 0000-0002-19436758; Ping Han ORCID: 0000-0002-9710-0037; Wuran Wei ORCID: 0000-0002-2348-8593
} 


\section{Introduction}

In the United States, prostate cancer (PC) is the most frequent cancer and the second leading cause of cancer death in men in men 60 years and older, with an estimated 191,930 new cases and 33,330 deaths in 2020 (1). Additionally, PC ranks first in terms of incidence and mortality in urologic cancer tumors in Chinese men (2). Prostate-cancer-specific mortality was low (approximately $0.07 \%$ to $0.15 \%$ ) regardless of the treatment assigned at a 10-year median follow-up, with no significant difference among active monitoring, radical prostatectomy (RP), and external-beam radiotherapy (3). The choice of treatment depends on patient age, tumor stage and patient preference. $\mathrm{RP}$ is an effective curative strategy for localized PC to control disease progression and prevent metastasis. The procedure includes the removal of the entire prostate with its capsule intact and seminal vesicles, followed by undertaking vesico-urethral anastomosis (4). RP can be performed by open (ORP), laparoscopic (LRP) or robotassisted (RARP) approaches. Currently, it is difficult to draw conclusions on differences in oncological, patientdriven or erectile dysfunction (ED) outcomes between the approaches (4).

Urinary incontinence (UI) and ED are common postsurgical complications which are associated with decreased health-related quality of life (HRQL) and patient satisfaction (5). Depending on the definition of UI, approximately $80 \%$ of patients develop post-prostatectomy incontinence (6) and nearly $70 \%$ of patients are incontinent beyond 2 years (7). Pelvic floor muscle training (PFMT) has been introduced into male UI after RP due to its favorable efficacy on female stress UI (8). However, the effect of PFMT on male UI is limited. A recent Cochrane review conducted in 2015 concluded that no overall benefit at 12-month postoperatively was observed for patients with post-prostatectomy UI between postoperative PFMT group and control group and that PFMT may speed recovery of continence between $3 \mathrm{rd}$ and 12 th month (9). One potential reason for suboptimal efficacy of conventional PFMT (CPFMT) is the under-utilization of abdominals and other regional muscles that normally co-activate with the pelvic floor, such as the transverse abdominis (TrA), rectus abdominis, and the diaphragm (10). In this scenario, our aim is to assess whether advanced PFMT (APFMT) could facilitate recovery of UI following RP in comparison with CPFMT. We present the following article in accordance with the PRISMA reporting checklist (available at http:// dx.doi.org/10.21037/tau-20-615).

\section{Methods}

\section{Study selection}

In accordance with the Preferred Reporting Items for Systematic Review and Meta-analyses guidelines (11), a systematic literature search was performed to identify randomized controlled trials (RCTs) through electronic databases including PubMed, Embase, Cochrane Library and Web of Science from database inception to February 2020 without language limitation. All initially identified studies were further filtered based on the following predetermined relevant Medical Subject Heading (MeSH) terms and keywords: "pelvic floor muscle training" and "radical prostatectomy". The search strategy used in PubMed was as follows: (pelvic floor muscle training [Title/ Abstract]) AND radical prostatectomy [Title/Abstract]. Reference lists of related studies including reviews were also retrieved to ensure comprehensive search. A detailed search strategy is provided in Supplemental File. All RCTs that reported the following interesting results were pooled and analyzed. On the basis of titles and abstracts, study screening and selection were carried out independently by three authors (DCF, SZL, and DXL). Subsequently, articles that met the inclusion criteria were retrieved for full-text evaluation, and data were extracted by two independent reviewers (DCF, SZL). Discrepancies were resolved by another author $(\mathrm{PH})$. The manuscript was revised by the author (WRW). Data from all included studies were extracted and tabulated by one author and corroborated by a second. The extracted information were as follows: (I) the first author and publication year; (II) details of the study design (number of patients randomized, the method of randomization, and the length of observation); (III) the characteristics of the recruited patients; (IV) details of the interventions used; and (V) data relating to outcomes of interest.

\section{Selection criteria}

The eligibility of included studies was determined by the following PICOS approach: Patients (P): patients with PC undergoing RP, irrespective of surgical types; Intervention (I): APFMT refers to the coactivation of pelvic floor muscles and other regional muscles, such as Pfilates and 
Hypopressives; Comparison (C): studies comparing APFMT to CPFMT; Outcomes (O): Feasibility was assessed by attrition rate and adverse events; Efficacy was evaluated by continence rate which was measured according to a bladder diary, self-report (to determine the number and extent of incontinence episodes and number of pads used per day), a validated questionnaire (to determine the severity of urinary incontinence) or a pad test for measuring grams of urine lost; number of pads; pad weight; incontinence-related quality of life which was measured by the International Consultation on Incontinence Questionnaire - Short Form (ICIQ-SF); pelvic floor muscle strength (PFMS); pelvic floor muscle endurance (PFME). Outcomes were assessed at short-term (3 months after training completion, immediateterm was defined as 1 month after training completion), intermediate-term (3-6 months after training completion), and long-term (greater or equal to 6 months after training completion); Study design (S): RCTs published in full text. For articles with overlapping data of the same population source, only the largest report was included, unless they reported different outcomes of interest.

\section{Quality assessment}

The methodological quality of the included studies were evaluated by two independent authors (DCF, SZL) using the Cochrane Collaboration's Risk of Bias (RoB) tool in Review Manager software (https://community.cochrane. org/help/tools-and-software/revman-5). This tool evaluates the RCT process from 7 domains: random sequence generation (selection bias); allocation concealment (selection bias); blinding of participants and personnel (performance bias); blinding of outcome assessment (detection bias); incomplete outcome data (attrition bias); selective reporting (reporting bias); other bias (such as funding sources). Besides, two independently rated the level of evidence of included articles through the Oxford Centre for EvidenceBased Medicine criteria (12). This scale classified studies from strongest (level 1) to weakest (level 5) strength of evidence based on study design and data quality.

Figure 1 presents the RoB summary of the six RCTs (13-18). Taken together, included studies showed a low risk of bias in terms of selection, performance, detection, attrition and reporting.

\section{Statistical analysis}

The data analysis was conducted by the Review Manager (RevMan) Version 5.3 (The Nordic Cochrane Centre, the Cochrane Collaboration, Copenhagen, Denmark). Continuous variables were presented as mean difference (MD) or standard mean differences (SMD) and dichotomous data as relative risk (RR), both with $95 \%$ confidence intervals (CIs). Heterogeneity among studies was evaluated by the Cochran Q test (19) and $\mathrm{I}^{2}$ test (20), with $\mathrm{I}^{2}>50 \%$ regarded as being significant heterogeneity. The random effects model was used to analyze the data and sensitivity analysis was performed to detect the source of heterogeneity when the trials yielded heterogeneity $(\mathrm{P}<0.1)$, otherwise the fixed effects model was used. Statistical significance was established as $\mathrm{P}<0.05$. For data deemed not appropriate for synthesis, a narrative overview was conducted.

\section{Results}

\section{Search results}

Two hundred forty-four records were identified initially through a systematic literature search of electronic databases including PubMed, Embase, Cochrane Library and Web of Science from database inception to February 2020 without limitation to language. Besides, a manual search of reference lists of relevant articles and previous reviews was also conducted to broaden the retrieval. The eligibility of full-text articles was assessed after duplicates removed and preliminary screening of titles and abstracts, and 6 RCTs $(13-18)$ with a total of 564 patients from 5 countries were considered for final analysis. Figure 2 depicts the study flow diagram. 2 RCTs $(13,14)$ derived from the same research team. Pedriali et al. (13) published the initial results of Pilates in the rehabilitation of patients with UI after RP, which showed similar advantages of Pilates training over CPFMT. Gomes et al. (14) not only reported the intermediate-term outcomes of Pilates exercises compared to CPFMT but also evaluated its effect on PFMS. Thus, we incorporated these two RCTs into analyze in different conditions. The data on this topic are quite recent considering all studies published in the past four years. Table 1 details the main characteristics of the included studies in this meta-analysis.

\section{CPFMT versus Baseline}

For pad weight, meta-analysis of two studies $(15,17)$ with 122 participants receiving postoperative CPFMT found a significant improvement within one month after surgery (MD: $-28.95,95 \%$ CI: -32.12 to $-25.77 ; \mathrm{P}<0.00001)$, and there is a tendency to improve at short-term $(13,15)$ and 


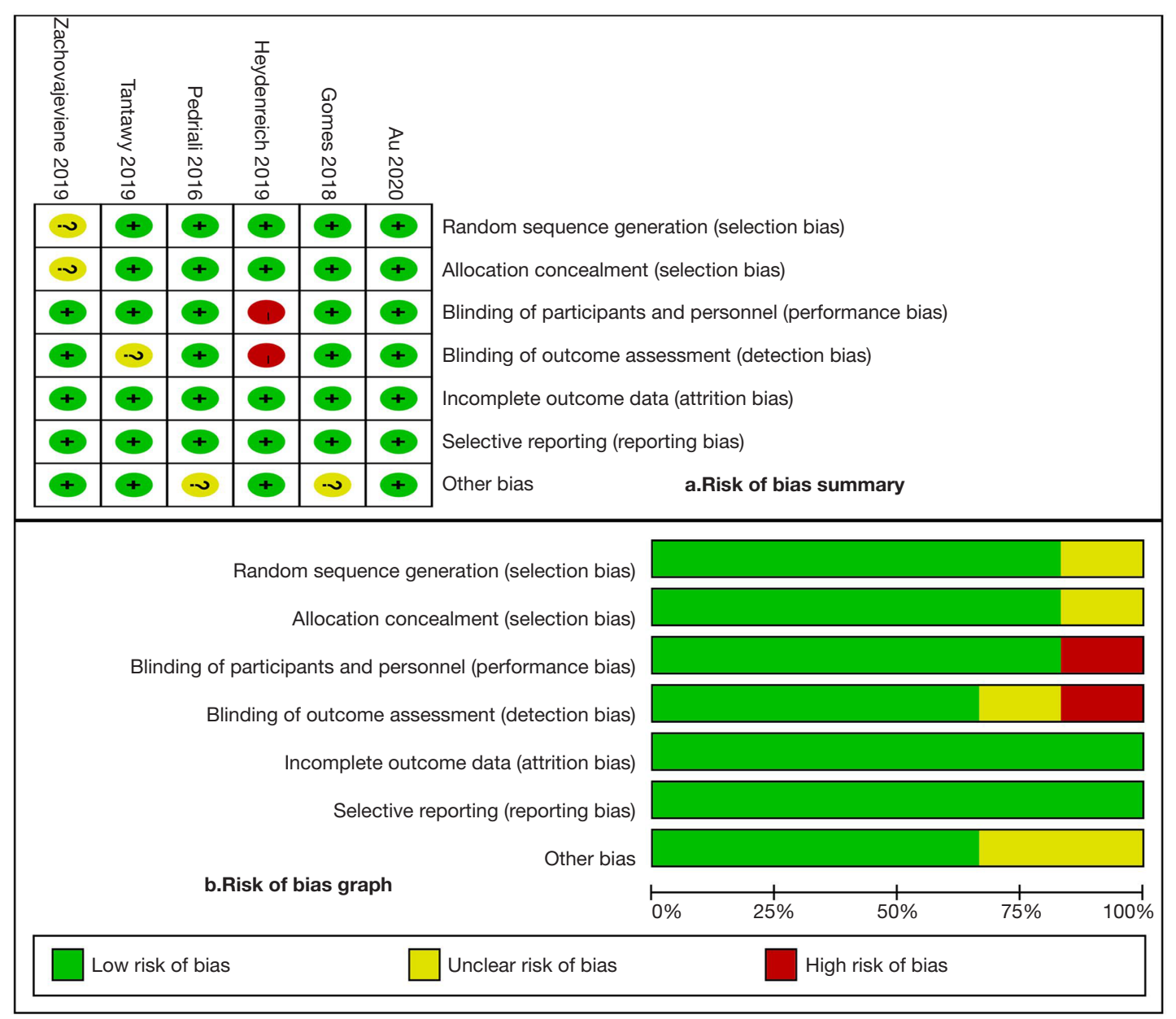

Figure 1 Risk of bias summary of included trials.

intermediate-term follow-up $(14,16)$. Data from one small study $(13, \mathrm{n}=28)$ identified a less number of pads per day at 10 weeks post-intervention $(0.82$ vs. 2.75$)$, and the overall effect was significant $(-1.93,95 \%$ CI: -2.56 to -1.30 ; $\mathrm{P}<0.00001)$. Besides, results from the same research team confirmed the previous findings in terms of pad number at a longer follow-up (14). Pooled analysis of two studies $(13,15)$ showed superiority of CPFMT over baseline with regard to ICIQ-SF score at short-term follow-up (MD: $-6.27,95 \%$ CI: -10.90 to $-1.65 ; \mathrm{P}=0.008)$ and data from one small study (14) confirmed this at the 4-month followup (MD: $-5.85,95 \%$ CI: -7.75 to -3.95 ; $\mathrm{P}<0.00001)$. Data from two studies $(14,16)$ found a significant difference in favor of CPFMT compared to baseline in terms of PFME (MD: $5.51,95 \%$ CI: 4.52 to $6.50 ; \mathrm{P}<0.00001$ ), and there is a tendency to support the application of CPFMT concerning PFMS $(\mathrm{P}=0.06)$. Figure 3. details the meta-analysis results of CPFMT versus Baseline.

\section{APFMT versus Baseline}

For pad weight, meta-analysis of two studies $(15,17)$ with 123 participants receiving postoperative APFMT found a significant improvement within one month after surgery (MD: $-73.47,95 \% \mathrm{CI}:-49.66$ to $-43.14 ; \mathrm{P}=0.03)$ and 1 - to 3-month follow-up $(13,15)$ (MD: -93.08, 95\% CI: -156.65 to $-29.51 ; \mathrm{P}=0.004)$, and there is a tendency to improve at intermediate-term follow-up $(14,16)$. Data from one small study $(13, \mathrm{n}=26)$ identified a less number of pads per day at 10 weeks post-intervention ( $0.84 v s .2 .92)$, and the overall effect was significant $(-2.08,95 \%$ CI: -2.91 to -1.25 ; $\mathrm{P}<0.00001)$. Besides, results from the same research team confirmed the previous findings regarding pad number at a longer follow-up (14). Pooled analysis of two studies $(13,15)$ 


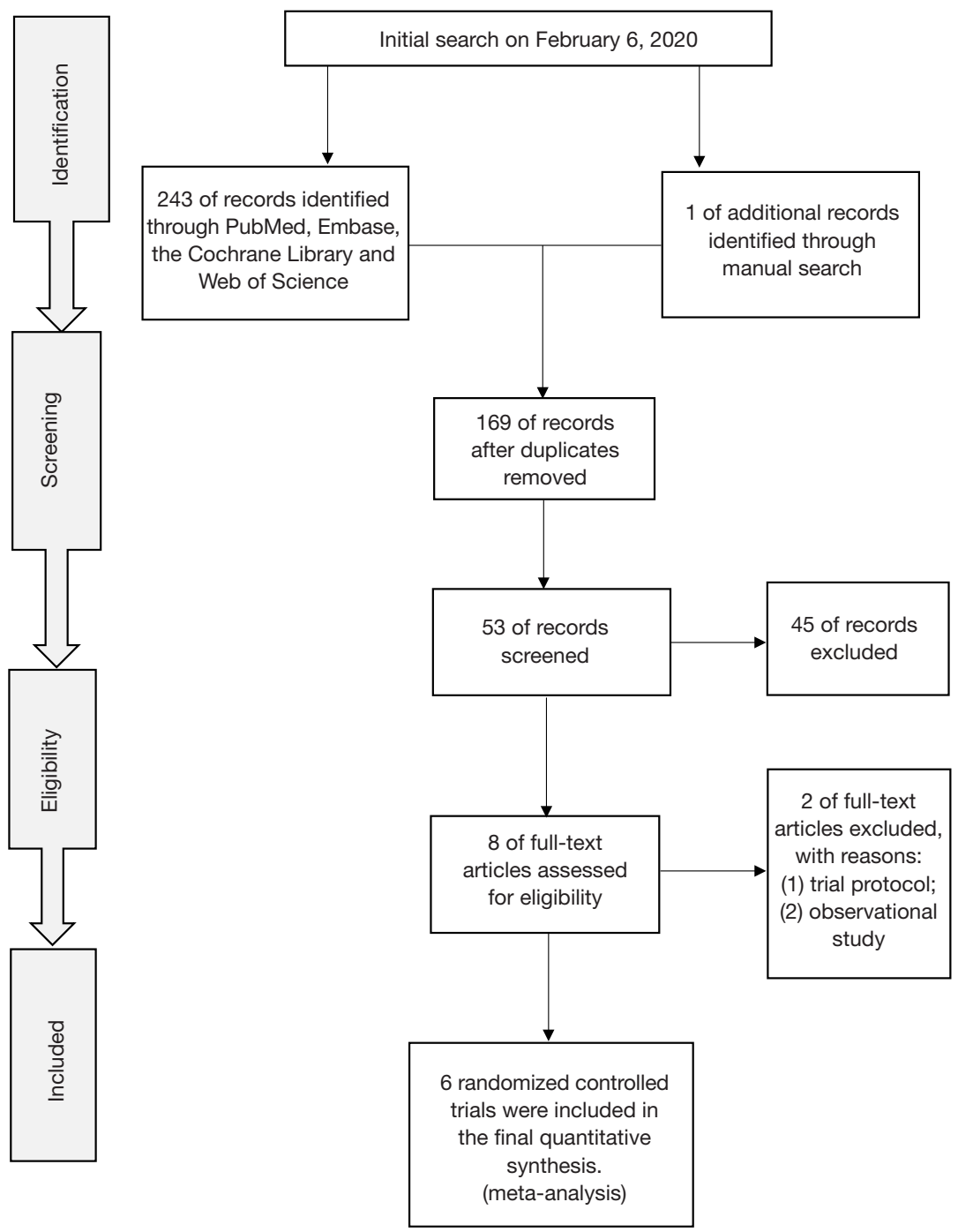

Figure 2 Study flow diagram.

showed superiority of APFMT over baseline with regard to ICIQ-SF score at short-term follow-up (MD: -10.05 , 95\% CI: -12.16 to $-7.94 ; \mathrm{P}<0.00001)$ and data from one small study (14) confirmed this at the 4-month follow-up (MD: $-8.44,95 \%$ CI: -10.57 to $-6.31 ; \mathrm{P}<0.00001)$. Data from two studies $(14,16)$ found a significant difference in favor of APFMT compared to baseline in terms of PFME (MD: 7.56, 95\% CI: 6.70 to 8.42 ; $\mathrm{P}<0.00001$ ) and PFMS (MD: 21.29, $95 \%$ CI: 17.79 to 24.78 ; $\mathrm{P}<0.00001)$. Figure 4 details the meta-analysis results of APFMT versus Baseline.

\section{APFMT versus CPFMT}

No adverse events were reported in all included studies (13-
18). Patients receiving APFMT had a similar attrition rate to those receiving CPFMT (18/236 vs. 22/282, $\mathrm{P}=0.61)$. Two studies $(13,15)$ reported the numbers of participants with short-term continent status and three studies $(14,16,18)$ reported the numbers of patients with intermediate-term continent status. No significant difference was observed between APFMT group and CPFMT group irrespective of short-term $(\mathrm{P}=0.08)$ and intermediate-term followup $(\mathrm{P}=0.31)$. Data from one small study (13) found no significant difference between APFMT group and CPFMT group at 10 weeks follow-up $(P=0.95)$ in terms of pad number, but the same research team identified a smaller number of pads per day in favor of APFMT $(0.73 \pm 1.26$, $\mathrm{n}=34$ vs. $1.48 \pm 1.31, \mathrm{n}=35$ ) compared with CPFMT at 


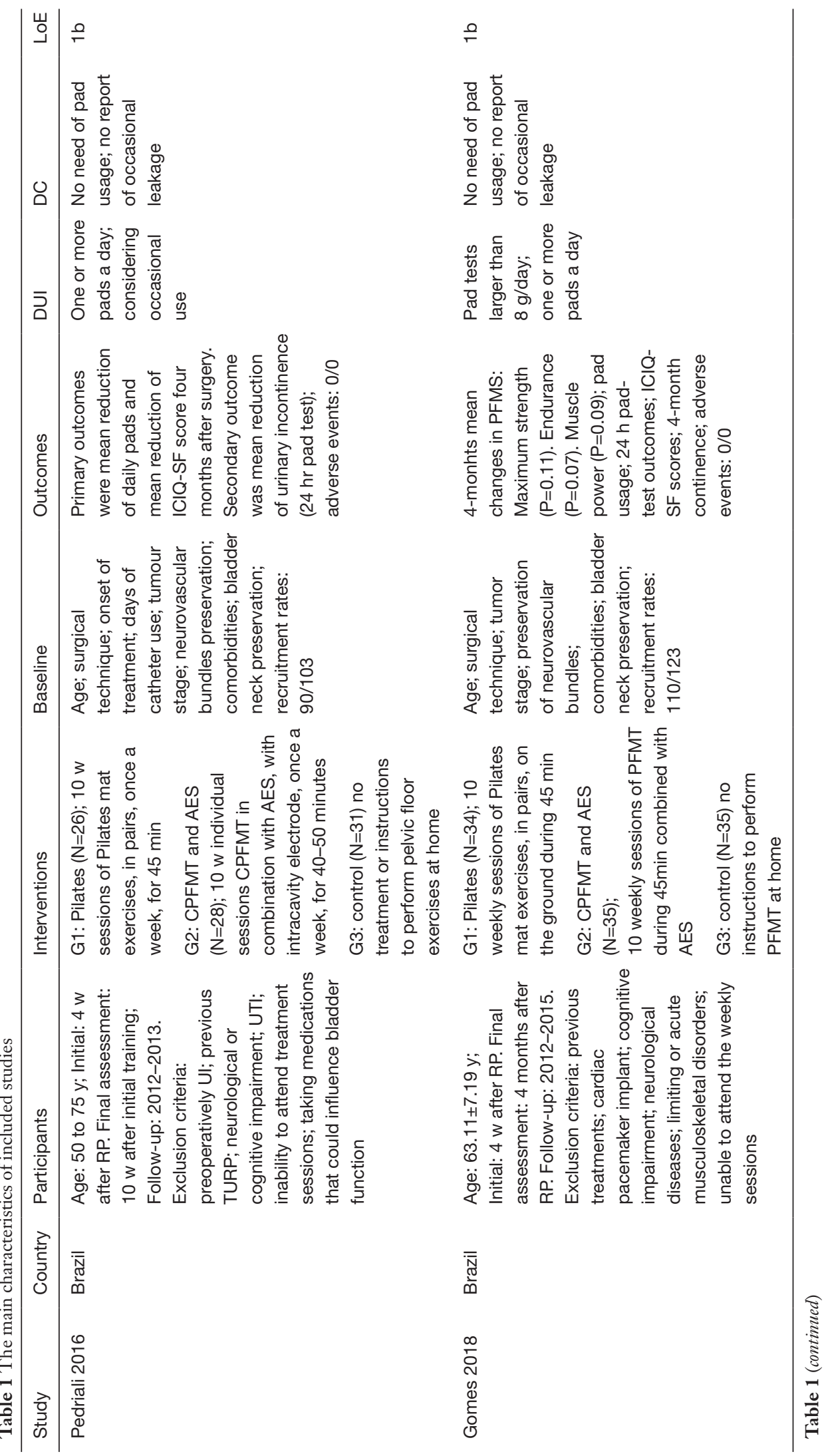




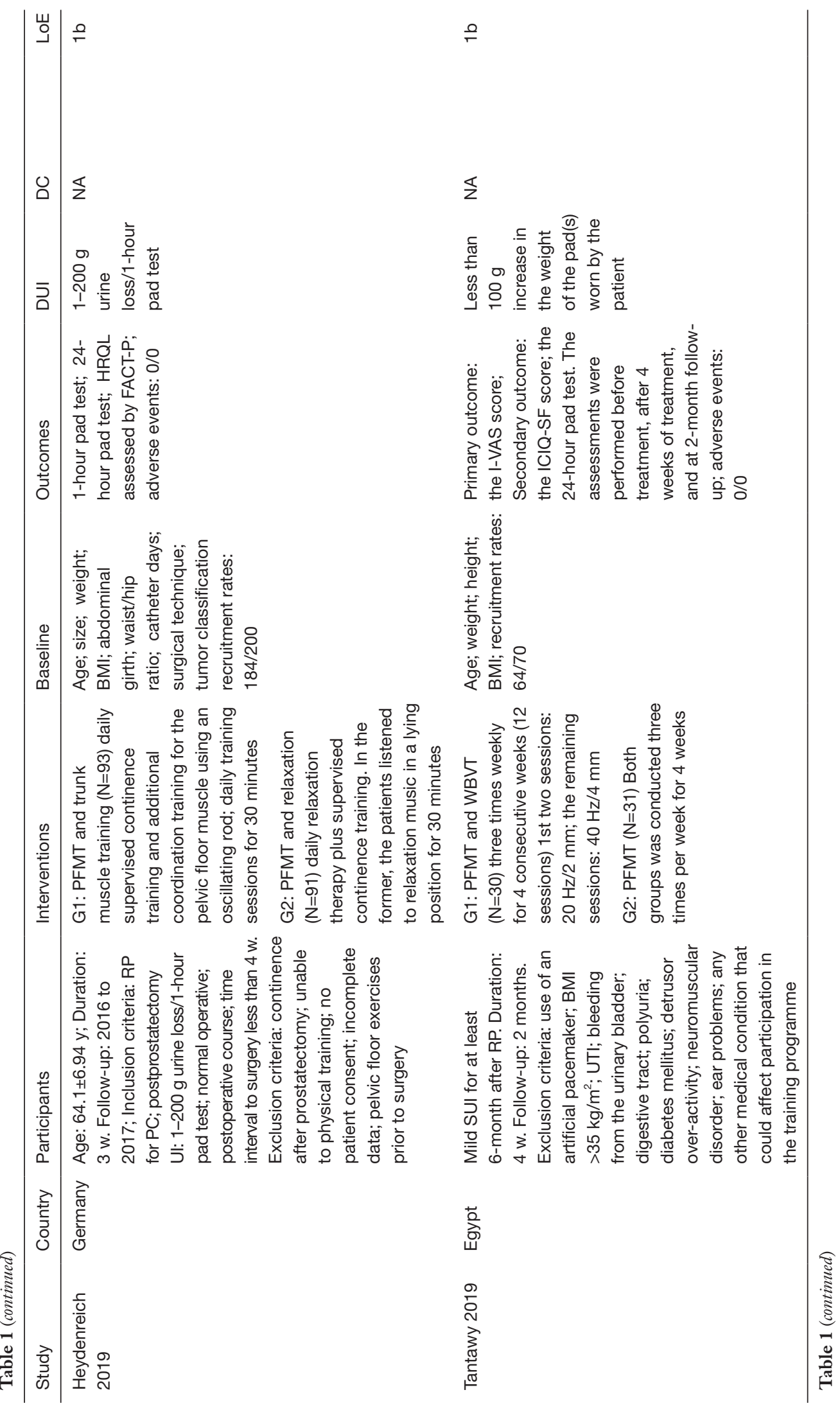




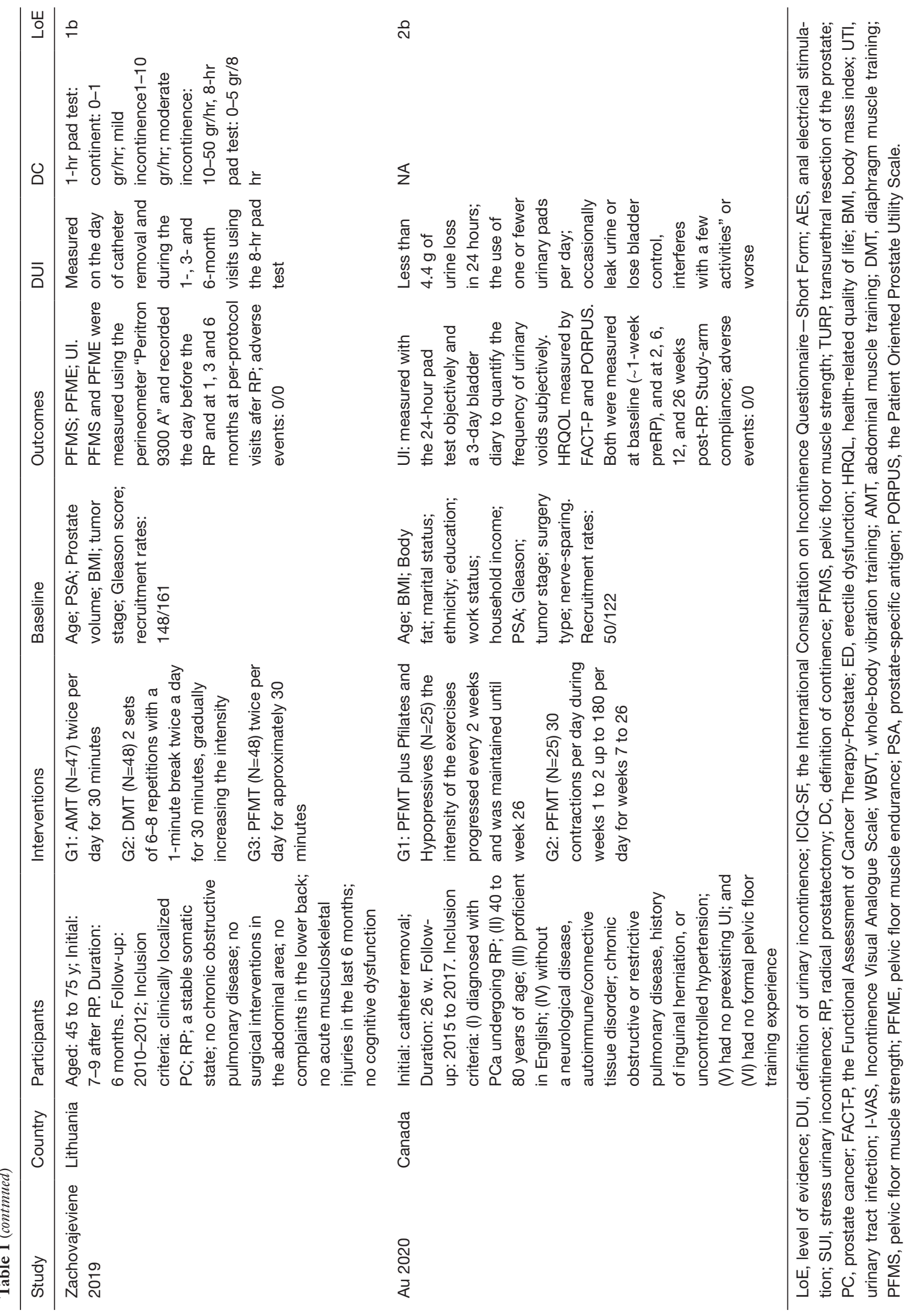


CPFMT vs Baseline Pad weight

within 1 montl

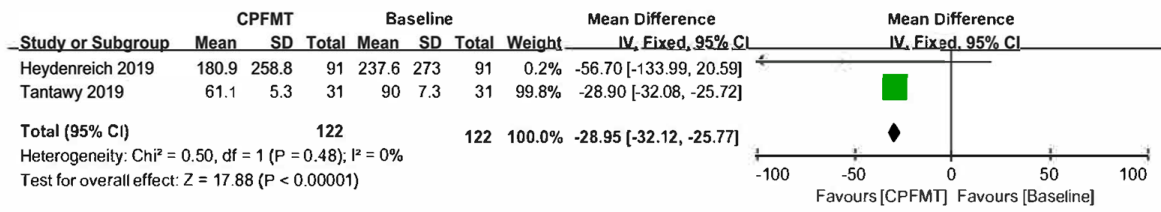

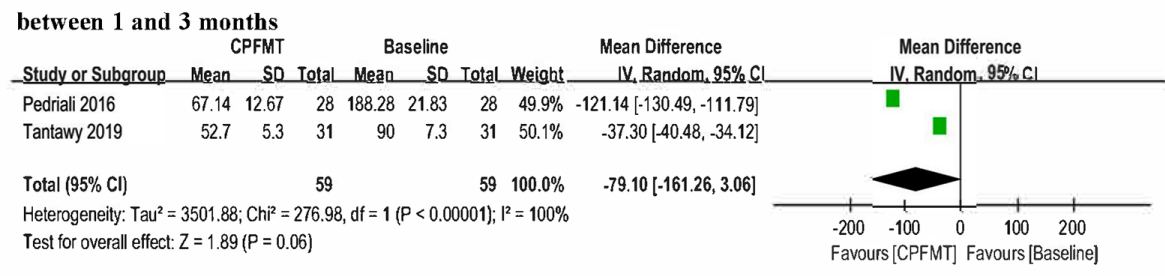

between 3 and 6 months

$$
\text { CPFMT Baseline Std. Mean Difference Std. Mean Difference }
$$

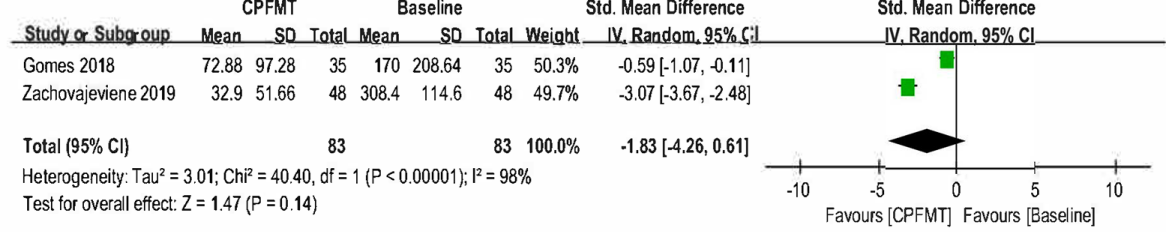

Pad number

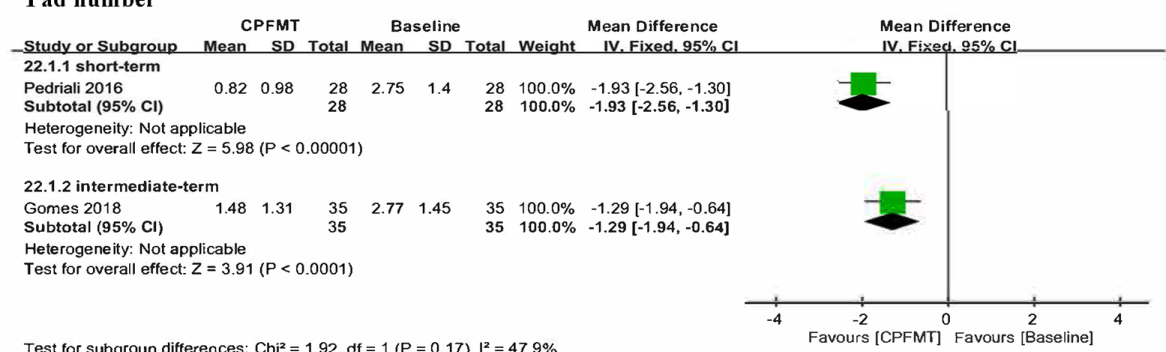

\section{ICIQ-SF score}
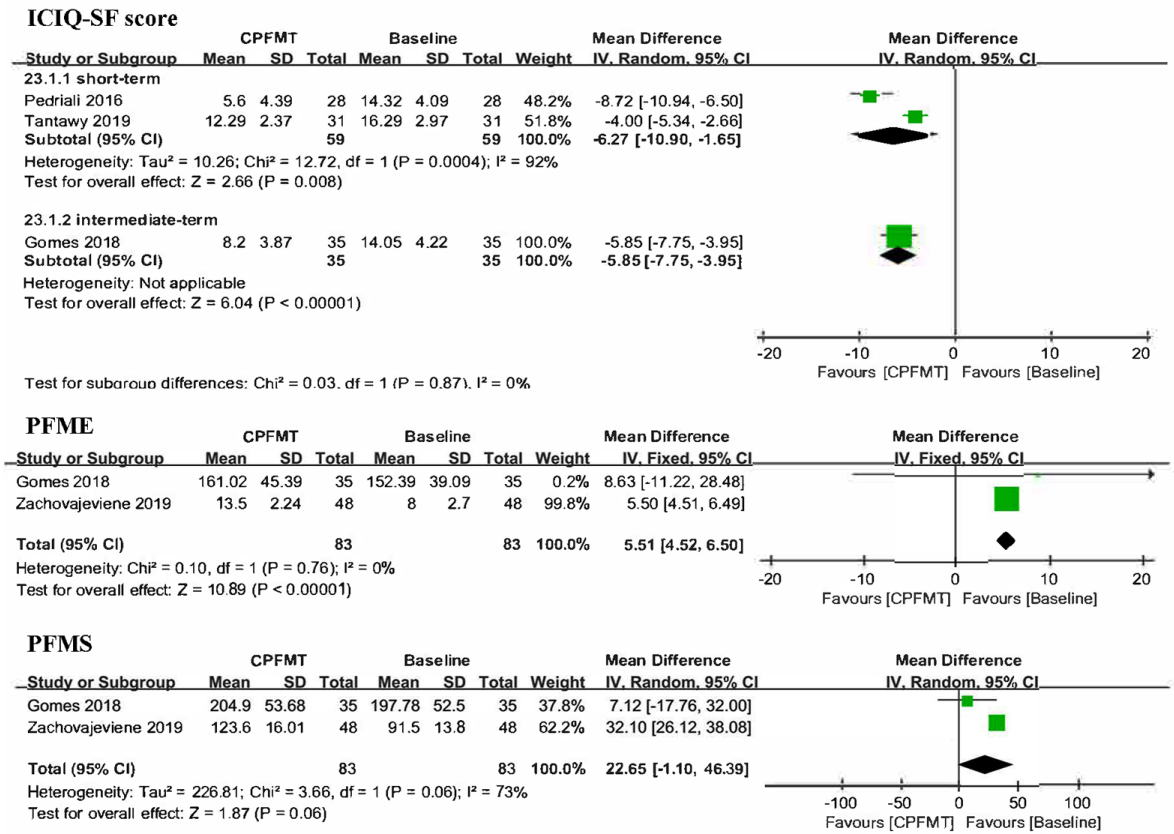

Figure 3 The meta-analysis results of CPFMT versus Baseline. CPFMT, conventional pelvic floor muscle training. 


\section{APFMT vs Baseline Pad weight}

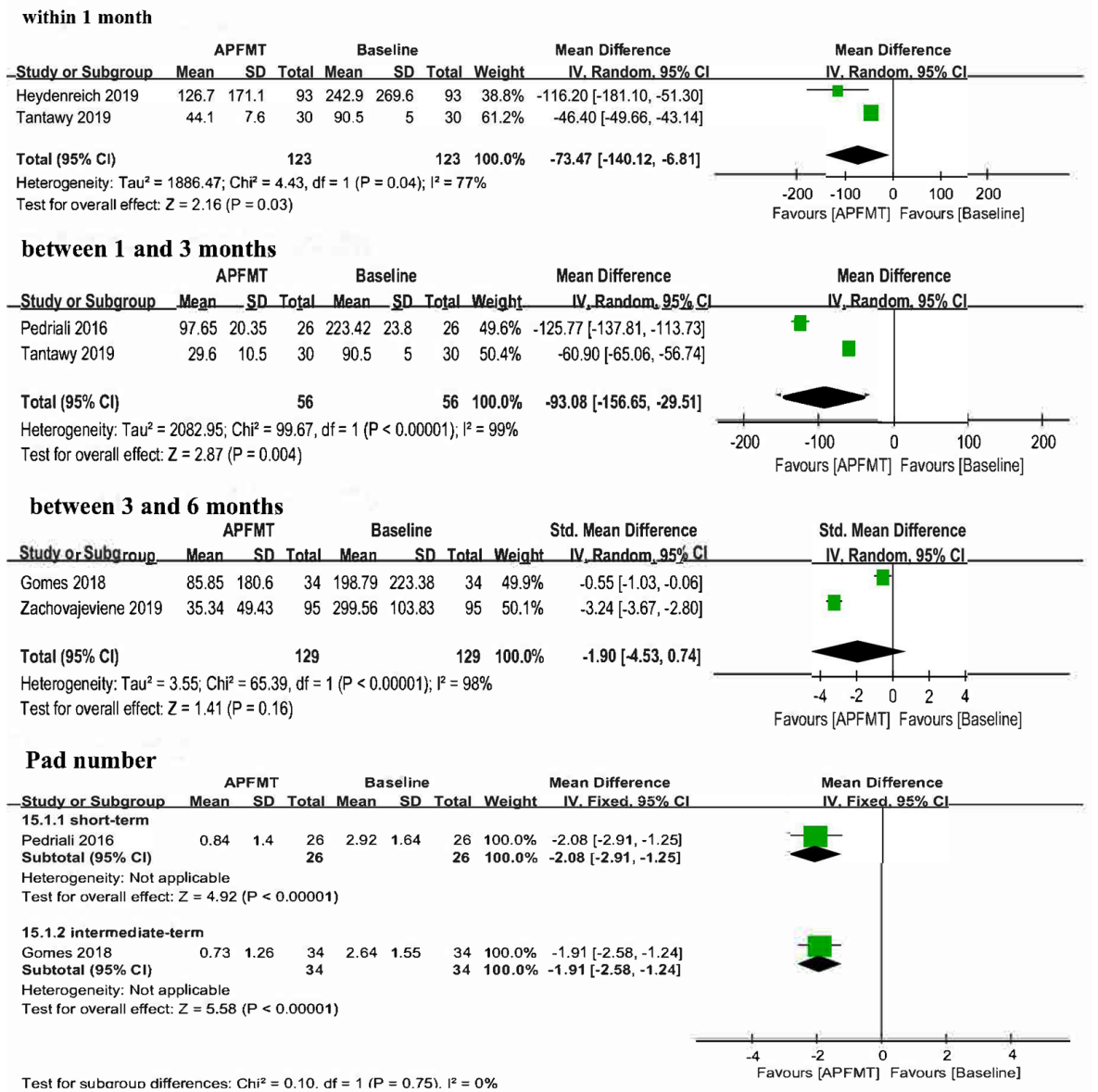

\section{ICIQ-SF score}
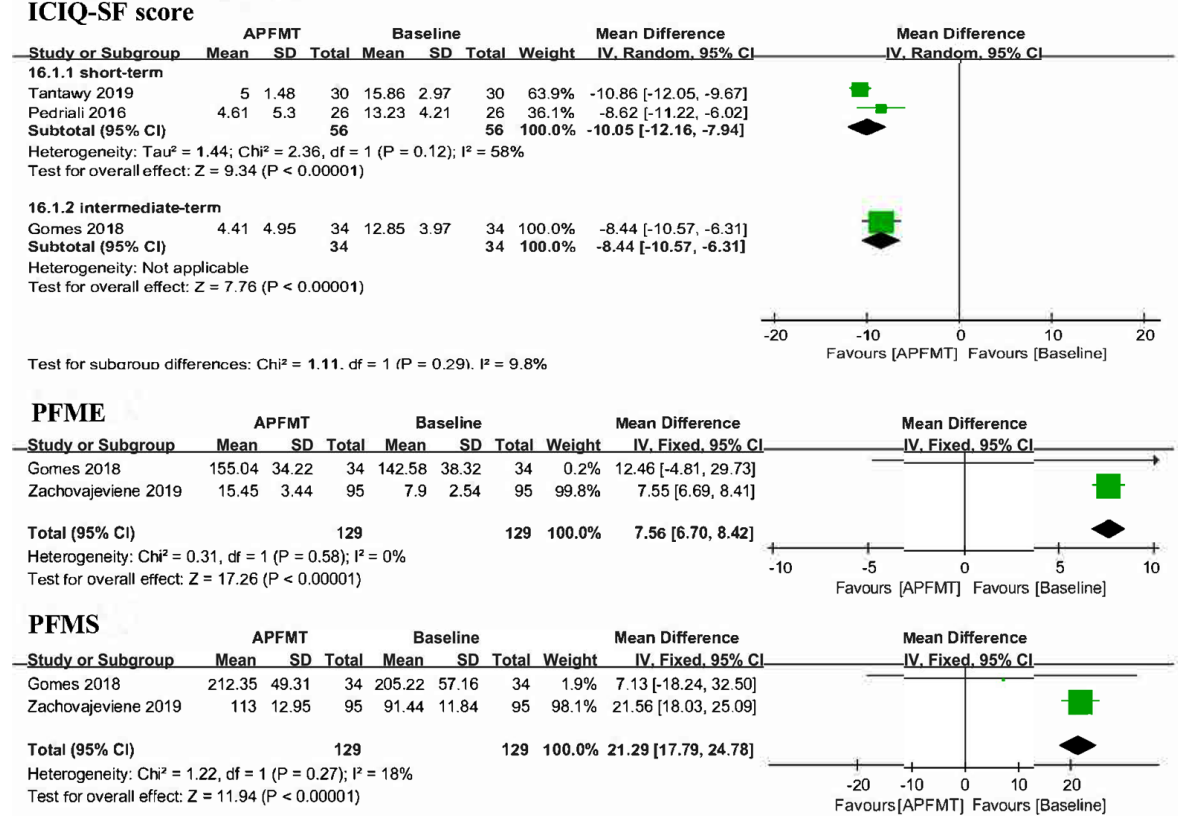

Figure 4 The meta-analysis results of APFMT versus Baseline. APFMT, advanced pelvic floor muscle training. 
4-month follow-up and the overall effect was significant (MD: -0.75 , 95\% CI: -1.36 to $-0.14 ; \mathrm{P}=0.02$ ). Pooled analysis of two studies $(13,15)$ with 115 patents (56 in the APFMT and 59 in the CPFMT) observed a tendency in favor of APFMT group compared to CPFMT group with regard to ICIQ-SF score at short-term follow-up. One study (14) reported a less ICIQ-SF score in patients with APFMT group compared with those in CPFMT group, and the overall effect was significant (MD: $-3.79,95 \% \mathrm{CI}$ : -5.89 to $-1.69 ; \mathrm{P}=0.0004)$. Pooled analysis of two studies $(14,16)$ showed a significantly longer duration of PFME in APFMT group (MD: 1.93, 95\% CI: 0.99 to 2.87; $\mathrm{P}<0.0001$ ) than their counterpart; however, there was no significant difference between these two groups in terms of PFMS $(\mathrm{P}=0.48)$. For pad weight, meta-analyses of two studies $(15,17)$ and another two studies $(14,18)$ indicated significant superiority of APFMT over CPFMT withing 1 month after surgery (MD: -17.10 , 95\% CI: -20.39 to -13.81 ; $\mathrm{P}<0.00001)$ and at 3 - to 6-month follow-up (MD: -1.40 , 95\% CI: -1.70 to $-1.00 ; \mathrm{P}<0.00001)$, respectively. However, data from three studies $(13,15,18)$ detected no significant difference between APFMT group and CPFMT group at 1 - to 3 -month follow-up $(\mathrm{P}=0.86)$, and pooled analysis of two studies $(16,18)$ also observed no significant difference between these two interventions at greater than 6-month follow-up $(\mathrm{P}=0.35)$. Figure 5 depicts outcomes of APFMT versus CPFMT in this meta-analysis.

\section{Discussion}

$\mathrm{UI}$ is a predictable bothersome post-prostatectomy sequela which can persist for two years or longer and severely negatively interferes with patients' quality of life, such as partner relationships, sexual life, and energy levels $(18,21)$. Besides, long-term effects of UI on patients include social disorders, insufficient self-confidence, loss of interest in daily living and increasing economic burden $(10,22)$. Subsequently, UI has been deemed most concerned outcome for decreased health-related quality of life during the early post-RP period and has been closely associated with patients' dissatisfaction after surgery (18). Accordingly, rehabilitation of UI is paramount in the setting of prevalence of RP in the management of PC and the associated psychosocial, functional and economic adversity caused by UI $(10,18)$.

Despite advances in robotic technique since its description in 2002 (4), RARP showed no decreased incontinence rates than other approaches (23). Considering the success of PFMT in female stress UI, CPFMT has been attempted in patients undergoing RP $(6,8)$. However, a recent systematic review and meta-analysis (9) of the available studies showed limited efficacy of CPFMT on the management of UI after RP despite promising early outcomes in some trials $(24,25)$. This may be related to different mechanisms of UI in men and women. The female incontinent mechanism is usually associated with the levator ani muscles dysfunction secondary to pregnancy and vaginal birth $(6,26)$, whereas in men after RP, it is hypothesized to result from injury to the internal urethral sphincter and/ or an onset of bladder detrusor hyperactivity that lead to urge incontinence through pressure on the bladder walls $(6,10)$. Besides, there are different techniques for RP and these techniques can lead to different UI rates, which may be a possible limit of the PFMT on the recovery of continence. Anatomically, the pelvic floor muscles are comprised of the internal sphincter muscle, levator ani, coccygeus, striated urogenital sphincter, external anal sphincter, ischiocavernosus, and bulbospongiosus which work in a coordinated fashion to maintain urinary continent status (27). Therefore, continence is highly contingent upon the support of external urethral sphincter by pelvic floor musculature (10). CPFMT facilitate improved capability for external urethral constriction and relaxed detrusor activity through hypertrophy of the periurethral striated muscles, a resultant stiffening and strengthening of the pelvic floor muscles and connective tissues, and an inhibition reflex of the detrusor muscles to increase strength, endurance, and coordination of the pelvic floor muscles and functional activation of the external urethral sphincter (10). This is consistent with the findings of our study that CPFMT had a longer postoperative PFME, lower ICIQ-SF score, smaller number of pads per day and pad weight at 1-month follow-up than baseline. At the same time, other conservative adjuvant treatments, such as biofeedback sessions $(28,29)$, electrical stimulation $(29,30)$, physiotherapist-guided therapy $(31,32)$ and extracorporeal magnetic innervation system $(33,34)$, have been demonstrated inconsistent findings concerning their efficacy by previous meta-analysis (28-32) and clinical trials $(33,34)$. However, none of these reviews included trials that incorporated training of the surrounding muscles, which have been demonstrated to facilitate optimal pelvic floor contractions in growing literatures (10,35-39). These surrounding muscles, particularly TrA, rectus abdominis, and diaphragm muscles, are usually ignored in PFMT approaches despite their requirement for optimal pelvic floor activation $(10,35,38)$. Junginger et al. (40) indicated that the pelvic floor muscle and TrA might be activated synergistically under the circumstance of electromyography. 

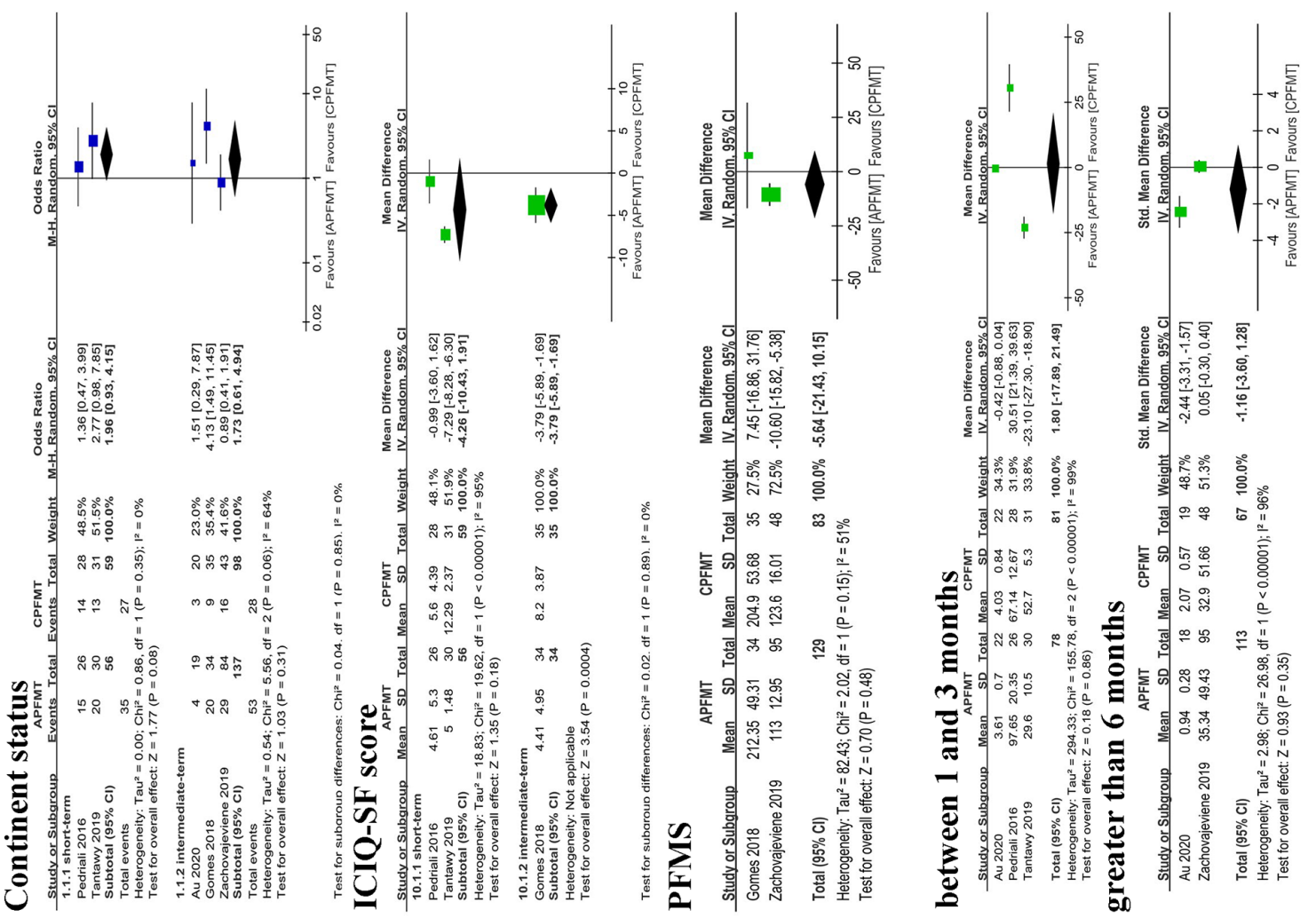

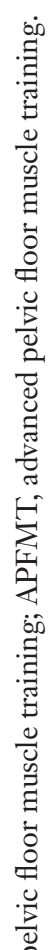
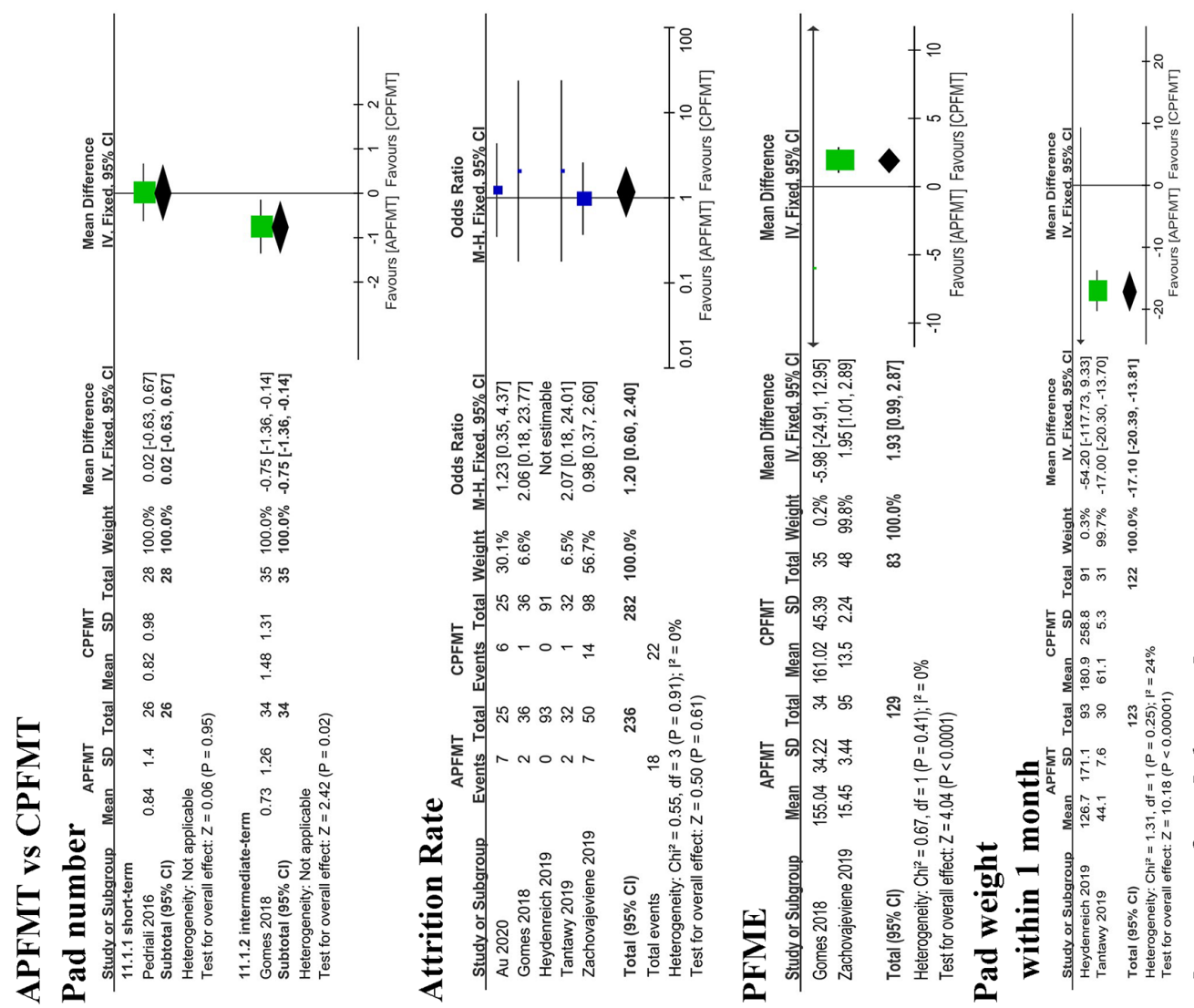

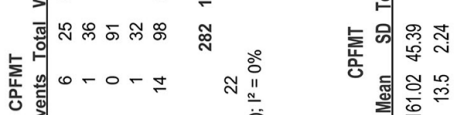
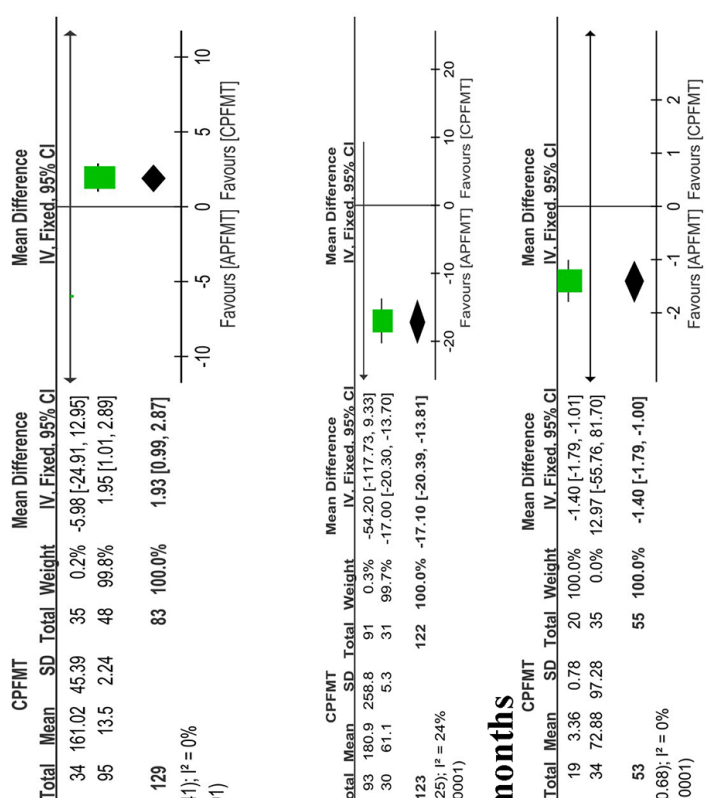

可带要

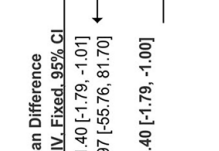

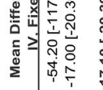

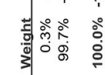

and

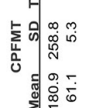

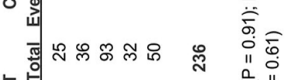

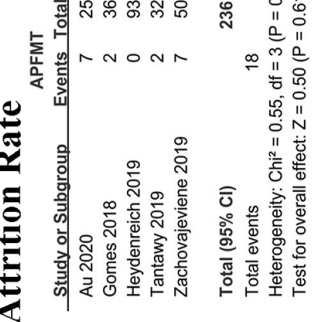
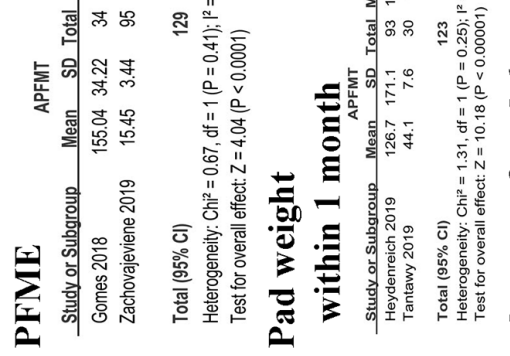

(3)

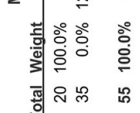

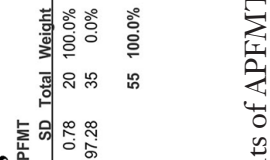

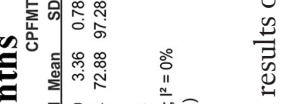

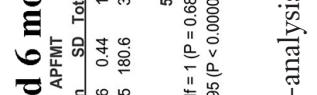

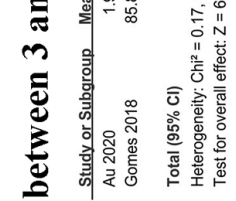

焉 
If it is difficult for TrA to maintain contractions, the possibility of poor pelvic floor tone (autonomic contraction) and consequently risk of UI might increase (18). This is consistent with the findings of Neumann and his colleagues (38). They showed that relaxation of the abdominal wall during pelvic floor muscle contraction only provokes $25 \%$ of the maximal voluntary contraction of the pelvic floor $(10,38)$. Moreover, diaphragm muscle training has also been shown to be associated with improvement of pelvic floor muscle activation and the reduction of intraabdominal pressure in women with incontinence $(10,35)$. In this scenario, the goal of current PFMT paradigms is optimizing pelvic floor muscle responsiveness and contraction quality through the utilization of other regional muscles (10). Such approaches included "Pfilates" ("Pelvic Floor Pilates') that contains the fundamental elements of Pilates (a form of exercise that focuses on core strength, stability, flexibility, and muscle control, as well as posture and breathing) with targeted pelvic floor activation $(10,41,42)$, "Hypopressives" focusing on conscious coordination of diaphragm and $\operatorname{TrA}$ with breathing $(10,35)$, trunk muscle (35) and even whole-body muscles (15). Our study also confirmed that APFMT had beneficial effects on pad weight, consumption of pads, ICIQ-SF, PFME and PFMS at short-term follow-up when compared to baseline.

In additional, Santa Mina et al. (10) reported a RCT protocol to determine the efficacy of APFMT on postprostatectomy UI in comparison with CPFMT. From then on, Pedriali et al. (13) reported the first study on Pilates in the recovery of patients with UI after RP, and. Gomes et al. (14) updated the results with more participants and longer follow-up period, and concentrated on PFME, PFMS and pelvic muscle power. They found a moderate inverse correlation has been identified between muscle power and 24-hour pad test in APFMT (14). Subsequently, several trials published their findings of APFMT compared to CPFMT (15-18). Our study indicated that APFMT and CPFMT were feasible owing to low attrition rate and no adverse events reported. Patients in APFMT group had comparable effect on short-term outcomes when compared to those in CPFMT group, and provided intermediate-term advantages over CPFMT group in terms of pad number, ICIQ-SF score, PFME and pad weight. These findings suggested that APFMT might facilitate the recovery of UI after RP.

To our knowledge, a meta-analysis comparing APFMT to CPFMT has not been previously reported. However, the present study does have the following unignored limitations. Firstly, the findings in this systematic review need to be considered cautiously because it remains difficult to identify the actual value of APFMT due to no enough RCTs (only 2 or 3 ) with large sample sizes. Furthermore, the effect of APFMT on treatment of UI in men after RP is yet to be defined, and there is insufficient information on all the benefits of this conservative treatment. Secondly, the broad heterogeneity in study designs, training approaches and definitions of outcome measures make us unable to draw a definite conclusion. Thirdly, the long-term efficacy of the two groups is unknown. Additionally, the cumbersome procedures of training may make it impossible for patients to persist for a long time. Future studies evaluating strategies to increase compliance to a pelvic floor muscle training regimen were warranted. At last, different RP techniques have different UI rates, which may limit the efficacy of PFMT on the recovery of continence. Consequently, the evidence is limited. Despite various pitfalls, our study does provide some reference value for clinical practice.

\section{Conclusions}

Current evidence indicated that APFMT might facilitate the recovery of UI after RP according to intermediate-term advantages over CPFMT in terms of pad number, ICIQSF score, PFME and pad weight. Further standardized, physiotherapist-guided and well-designed clinical trials conducted by large multicenter and experienced multidisciplinary clinicians are still warranted.

\section{Acknowledgments}

Funding: This work was supported by the 1.3 .5 project for disciplines of excellence, West China Hospital, Sichuan University (ZY2016104) and Pillar Program from Department of Science and Technology of Sichuan Province (2018SZ0219). The funders had no role in study design, data collection or analysis, preparation of the manuscript, or the decision to publish.

\section{Footnote}

Reporting Checklist: The authors have completed the PRISMA reporting checklist. Available at http://dx.doi. org/10.21037/tau-20-615

Conflicts of Interest: All authors have completed the ICMJE uniform disclosure form (available at http://dx.doi. org/10.21037/tau-20-615). The authors have no conflicts of interest to declare. 
Ethical Statement: The authors are accountable for all aspects of the work in ensuring that questions related to the accuracy or integrity of any part of the work are appropriately investigated and resolved.

Open Access Statement: This is an Open Access article distributed in accordance with the Creative Commons Attribution-NonCommercial-NoDerivs 4.0 International License (CC BY-NC-ND 4.0), which permits the noncommercial replication and distribution of the article with the strict proviso that no changes or edits are made and the original work is properly cited (including links to both the formal publication through the relevant DOI and the license). See: https://creativecommons.org/licenses/by-nc-nd/4.0/.

\section{References}

1. Siegel RL, Miller KD, Jemal A. Cancer statistics, 2020. CA Cancer J Clin 2020;70:7-30.

2. Zheng RS, Sun KX, Zhang SW, et al. Report of cancer epidemiology in China, 2015. Zhonghua Zhong Liu Za Zhi 2019;41:19-28.

3. Hamdy FC, Donovan JL, Lane JA, et al. 10-Year Outcomes after Monitoring, Surgery, or Radiotherapy for Localized Prostate Cancer. N Engl J Med 2016;375:1415-24.

4. Mottet N, Cornford P, van den Bergh RCN, et al. EAU Guidelines on prostate cancer. Access date, 2020: Available online: https://uroweb.org/guideline/prostatecancer/\#note_353

5. Chen C, Chen Z, Wang K, et al. Comparisons of healthrelated quality of life among surgery and radiotherapy for localized prostate cancer: a systematic review and metaanalysis. Oncotarget 2017;8:99057.

6. Hodges PW, Stafford RE, Hall L, et al. Reconsideration of pelvic floor muscle training to prevent and treat incontinence after radical prostatectomy. Urol Oncol 2020;38:354-71.

7. Stanford JL, Feng Z, Hamilton AS, et al. Urinary and sexual function after radical prostatectomy for clinically localized prostate cancer: the prostate cancer outcomes study. JAMA 2000;283:354-60.

8. Dumoulin C, Hay-Smith J. Pelvic floor muscle training versus no treatment, or inactive control treatments, for urinary incontinence in women. Cochrane Database Syst Rev 2010;(1):CD005654.

9. Anderson CA, Omar MI, Campbell SE, et al. Conservative management for postprostatectomy urinary incontinence.
Cochrane Database Syst Rev 2015;1:CD001843.

10. Santa Mina D, Au D, Alibhai SM, et al. A pilot randomized trial of conventional versus advanced pelvic floor exercises to treat urinary incontinence after radical prostatectomy: a study protocol. BMC Urol 2015;15:94.

11. Moher D, Liberati A, Tetzlaff J, et al. Preferred reporting items for systematic reviews and meta-analyses: the PRISMA statement. PLoS Med 2009;6:e1000097.

12. Evidence-Based Cf. Oxford Centre for evidence-based medicine: levels of evidence, 2009. Available online: http:// www.cebm.net/oxford-centreevidence-based-medicinelevels-evidence-march-2009/

13. Pedriali FR, Gomes CS, Soares L, et al. Is pilates as effective as conventional pelvic floor muscle exercises in the conservative treatment of post-prostatectomy urinary incontinence? A randomised controlled trial. Neurourol Urodyn 2016;35:615-21.

14. Gomes CS, Pedriali FR, Urbano MR, et al. The effects of Pilates method on pelvic floor muscle strength in patients with post-prostatectomy urinary incontinence: A randomized clinical trial. Neurourol Urodyn 2018;37:346-53.

15. Tantawy SA, Elgohary HMI, Abdelbasset WK, et al. Effect of 4 weeks of whole-body vibration training in treating stress urinary incontinence after prostate cancer surgery: a randomised controlled trial. Physiotherapy 2019;105:338-45.

16. Zachovajeviene B, Siupsinskas L, Zachovajevas P, et al. Effect of diaphragm and abdominal muscle training on pelvic floor strength and endurance: results of a prospective randomized trial. Sci Rep 2019;9:19192.

17. Heydenreich M, Puta C, Gabriel HH, et al. Does trunk muscle training with an oscillating rod improve urinary incontinence after radical prostatectomy? A prospective randomized controlled trial. Clin Rehabil 2020; 34:320-33.

18. Au D, Matthew AG, Alibhai SMH, et al. Pfilates and Hypopressives for the Treatment of Urinary Incontinence After Radical Prostatectomy: Results of a Feasibility Randomized Controlled Trial. PM R 2020;12:55-63.

19. Higgins JP, Thompson SG, Deeks JJ, et al. Measuring inconsistency in meta-analyses. BMJ 2003;327:557-60.

20. Higgins JP, Thompson SG. Quantifying heterogeneity in a meta-analysis. Stat Med 2002;21:1539-58.

21. Martin AD, Nakamura LY, Nunez RN, et al. Incontinence after radical prostatectomy: a patient centered analysis and implications for preoperative counseling. J Urol 2011;186:204-8.

22. Broome BAS. The impact of urinary incontinence on self- 
efficacy and quality of life. Health Qual Life Outcomes $2003 ; 1: 35$.

23. Yaxley JW, Coughlin GD, Chambers SK, et al. Robotassisted laparoscopic prostatectomy versus open radical retropubic prostatectomy: early outcomes from a randomised controlled phase 3 study. Lancet 2016;388:1057-66.

24. Van Kampen M, De Weerdt W, Van Poppel H, et al. Effect of pelvic-floor re-education on duration and degree of incontinence after radical prostatectomy: a randomized controlled trial. Lancet 2000;355:98-102.

25. Parekh AR, Feng MI, Kirages D, et al. The role of pelvic floor exercises on post-prostatectomy incontinence. J Urol 2003;170:130-3.

26. Delancey JO, Kane Low L, Miller JM, et al. Graphic integration of causal factors of pelvic floor disorders: an integrated life span model. Am J Obstet Gynecol 2008;199:610.e1-5.

27. Messelink B, Benson T, Berghmans B, et al. Standardization of terminology of pelvic floor muscle function and dysfunction: report from the Pelvic Floor Clinical Assessment Group of the International Continence Society. Neurourol Urodyn 2005;24:374-80.

28. Hsu LF, Liao YM, Lai FC, et al. Beneficial effects of biofeedback-assisted pelvic floor muscle training in patients with urinary incontinence after radical prostatectomy: A systematic review and metaanalysis. Int J Nurs Stud 2016; 60:99-111.

29. Kannan P, Winser SJ, Fung B, et al. Effectiveness of Pelvic Floor Muscle Training Alone and in Combination With Biofeedback, Electrical Stimulation, or Both Compared to Control for Urinary Incontinence in Men Following Prostatectomy: Systematic Review and Meta-Analysis. Phys Ther 2018;98:932-45.

30. Zhu YP, Yao XD, Zhang SL, et al. Pelvic floor electrical stimulation for postprostatectomy urinary incontinence: a meta-analysis. Urology 2012;79:552-5.

31. Fernández RA, García-Hermoso A, Solera-Martínez M, et al. Improvement of Continence Rate with Pelvic Floor Muscle Training Post-Prostatectomy: A Meta-Analysis of

Cite this article as: Feng D, Liu S, Li D, Han P, Wei W. Analysis of conventional versus advanced pelvic floor muscle training in the management of urinary incontinence after radical prostatectomy: a systematic review and meta-analysis of randomized controlled trials. Transl Androl Urol 2020;9(5):20312045. doi:10.21037/tau-20-615
Randomized Controlled Trials. Urol Int 2015;94:125-32.

32. Wu ML, Wang CS, Xiao Q, et al. The therapeutic effect of pelvic floor muscle exercise on urinary incontinence after radical prostatectomy: a meta-analysis. Asian J Androl 2019;21:170-6.

33. Yokoyama T, Nishiguchi J, Watanabe T, et al. Comparative study of effects of extracorporeal magnetic innervation versus electrical stimulation for urinary incontinence after radical prostatectomy. Urology 2004;63:264-7.

34. Koo D, So SM, Lim JS. Effect of Extracorporeal Magnetic Innervation (ExMI) Pelvic Floor Therapy on Urinary Incontinence after Radical Prostatectomy. Korean J Uro 2009;50:23-7.

35. Sapsford R. Rehabilitation of Pelvic Floor Muscles Utilizing Trunk Stabilization. Man Ther 2004;9:3-12.

36. Sapsford RR, Hodges PW. Contraction of the Pelvic Floor Muscles during Abdominal Maneuvers. Arch Phys Med Rehabil 2001;82:1081-8.

37. Sapsford RR, Hodges PW, Richardson CA, et al. Coactivation of the Abdominal and Pelvic Floor Muscles During Voluntary Exercises. Neurourol Urodyn 2001;20:31-42.

38. Neumann P, Gill V. Pelvic Floor and Abdominal Muscle Interaction: EMG Activity and Intra-Abdominal Pressure. Int Urogynecol J Pelvic Floor Dysfunct 2002;13:125-32.

39. Madill SJ, McLean L. Quantification of Abdominal and Pelvic Floor Muscle Synergies in Response to Voluntary Pelvic Floor Muscle Contractions. J Electromyogr Kinesiol 2008;18:955-64.

40. Junginger B, Baessler K, Sapsford R, et al. Effect of abdominal and pelvic floor tasks on muscle activity, abdominal pressure and bladder neck. Int Urogynecol J 2010;21:69-77.

41. Wells C, Kolt GS, Bialocerkowski A. Defining Pilates Exercise: A Systematic Review. Complement Ther Med 2012;20:253-62.

42. Culligan PJ, Scherer J, Dyer K, et al. A Randomized Clinical Trial Comparing Pelvic Floor Muscle Training to a Pilates Exercise Program for Improving Pelvic Muscle Strength. Int Urogynecol J 2010;21:401-8. 
OVID (Embase and Cochrane Library)

(pelvic floor muscle training and radical prostatectomy).kw. 10 records

PubMed

(pelvic floor muscle training [Title/Abstract]) AND radical prostatectomy [Title/Abstract] 74 records

Web of Science

Topic: (pelvic floor muscle training AND radical prostatectomy. 159 records 